\title{
First report of cassava leaf blight caused by Rhizoctonia solani AG-1 IA
}

\author{
Amauri Siviero $^{1}$ • Paulo E. F. de Macedo ${ }^{1} \cdot$ Giovanna T. S. Moreira ${ }^{1} \cdot$ Kátia L. Nechet $^{2} \cdot$ Regina M. S. Coelho $^{3}$. \\ Bernardo A. Halfeld-Vieira ${ }^{2}$ (D)
}

Received: 2 April 2019 / Accepted: 12 July 2019 / Published online: 20 July 2019

(C) Australasian Plant Pathology Society Inc. 2019

\begin{abstract}
Cassava (Manihot esculenta) plants were observed in the Amazon region showing extensive leaf blight. The identity of the pathogen was confirmed based on morphological characteristics and the sequence of ITS region of the rDNA. Koch's postulates were fulfilled and pathogenicity was demonstrated. Cassava leaf blight, caused by Rhizoctonia solani AG-1 IA, is reported for the first time in Brazil.
\end{abstract}

Keywords Thanatephorus cucumeris $\cdot$ Leaf blight $\cdot$ White thread $\cdot$ Manihot $\cdot$ Brazilian Amazon

Cassava (Manihot esculenta) is one of the most important agricultural crops in the Brazilian Amazon, with evidence that its domestication has occurred in the Amazon Basin (Moura et al. 2013). A severe leaf blight epidemic in cassava plantations was observed close to a native forest, in Mâncio Lima municipality, Acre state, Brazil, in 2018. Symptomatic plants presented extensive leaf blight, with plants frequently showing more than $60 \%$ of severity levels. Furthermore, lesions were also observed progressing towards the stem, frequently causing death of young plants (Fig. 1a). The signs of the pathogen consisted of conspicuous superficial hyphae on symptomatic tissues, often hanging necrotic leaves with a white thread.

Leaf samples with a dense white mycelial web were collected and after examination, more than 50 associations between symptoms and signs of a fungus with morphological characteristics of Rhizoctonia were observed. From a representative leaf sample, a portion of the mycelium was transferred to a Potato Dextrose Agar (PDA) culture medium supplemented with $50 \mathrm{ppm}$ Chloramphenicol (Sigma, China), thus obtaining a pure culture.

To determine the number of nuclei per cell, cultures were grown in PDA at $25^{\circ} \mathrm{C}$, for $24 \mathrm{~h}$. A portion of the hyphae was removed from the edge of the colony and placed on a glass

Bernardo A. Halfeld-Vieira

bernardo.halfeld@embrapa.br

Embrapa Acre, Rio Branco, AC, Brazil

Embrapa Meio Ambiente, Jaguariúna, SP, Brazil

3 Laboratório Nacional Agropecuário, Goiânia, GO, Brazil slide with a drop of alkaline safranin solution $(0,5 \%$ safranin, $10 \mathrm{~mL} \mathrm{KOH} \mathrm{3 \% ,} 5 \mathrm{~mL}$ glycerin, and $79 \mathrm{~mL}$ tap water). The hyphae were examined under an optical microscope, and the number of nuclei per cell was counted.

The anastomosis group (AG) was determined according to the technique presented by Ceresini et al. (1996). A mycelial disc of the isolate was transferred to a microscope slide and paired with each of the following tester strains of multinucleated Rhizoctonia solani groups obtained from the Culture Collection of Microorganisms of Environmental and Agricultural Importance (CMAA) at Embrapa Meio Ambiente, Jaguariúna, São Paulo, Brazil: AG-1 IA (CMAA 908) AG-1 IB (CMAA 909); AG-2 2 IIIB (CMAA 907); AG-3 (CMAA 906); AG-4 AHI (CMAA 903); AG-4 140 (CMAA 904); AG-7 H0 (CMAA 901); AG-BI TS-2-4 (CMAA 905). Each paired combination was maintained inside a Petri dish at $25{ }^{\circ} \mathrm{C}$ in the dark. Mycelial growth was observed in optical microscope several times a day until hyphal contact. The classification of the anastomosis reaction was observed at the point of hyphal contact assuming the criteria adopted by Parmeter et al. (1969).

To test Koch's postulates, $0.5 \mathrm{~mm}$-diameter mycelium discs of the associated fungus were deposited on the abaxial surface of detached cassava leaves over a moistened absorbent paper, and incubated inside plastic germination boxes, in the dark, at $25^{\circ} \mathrm{C}$. Each assay consisted of 3 repetitions of healthy leaves of cassava and two isolates of the associated fungus, and PDA discs with no mycelium growth were used as controls. After the development of the typical symptoms, the pathogen was reisolated from leaves to confirm the association with the aetiological agent.

For the sequencing of the internal transcribed spacer (ITS) region of the rDNA, genomic DNA of the pathogen was 


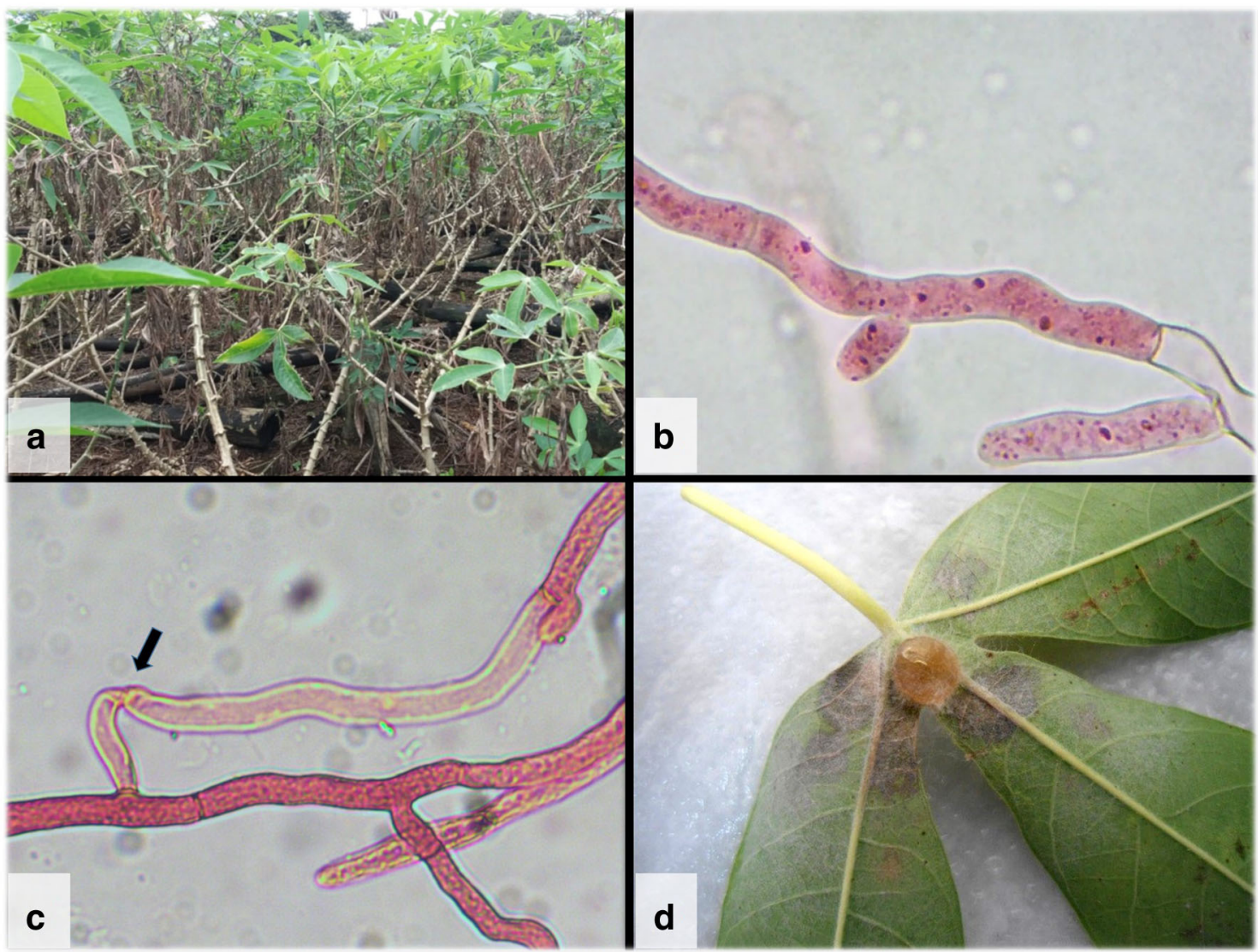

Fig. 1 a Leaf blight symptoms on field cassava plantation, b multinucleated hyphae, $\mathbf{c}$ hyphal fusion between CMAA 1734 isolate and tester strain of Rhizoctonia solani AG-1 IA (arrow), d symptoms and signs of $R$. solani CMAA 1734 on inoculated cassava leaf

extracted by using the DNeasy mericon Food Kit (Qiagen, Germany). The amplification of the ITS region was performed with the pair of primers ITS4 (5'-TCCTCCGCTTATTG ATATGC-3') and ITS5 (5'-GGAAGTAAAAGTCGTAACAA GG-3') (White et al. 1990), by using the Fungi-ITS amplification and sequencing protocol (Q-bank 2019). The PCR products were purified using ExoSAP kit (USB Corporation). Sequencing reactions were performed in ABI-Prism 3500 Genetic Analyzer (Applied Biosystems). A 685 bp resulting sequence was deposited in GenBank under accession no. MK503162.1 and then compared to other entries through BoldSystems (Ratnasingham and Hebert 2007) and BLAST searches in GenBank. Phylogenetic analyses were done by using ITS region from reliable AGs sequences of $R$. solani deposited in GenBank. Ceratobasidium ramicola CBS 758.79 was used as outgroup. Sequences were aligned with MUSCLE algorithm and phylogenetic analysis was done using Maximum likelihood method, with MEGA X software (Kumar et al. 2018).

Morphological characteristics revealed the associated fungus presented typical features of $R$. solani, such as microsclerotia formation in PDA culture medium, white-brownish mycelia, right-angled branching hyphae, and multinucleated cells (Fig. 1b). Hyphal fusion, characterised by the death of cells in anastomosis and adjacent cells, was observed only for pairing with tester strain AG-1 IA (Fig. 1c).

The isolate showed $99.68 \%$ of similarity with Rhizoctonia solani (tel. Thanatephorus cucumeris) using the Barcode of Life Data System-BOLD (Ratnasingham and Hebert 2007). BLAST searches revealed that the obtained sequence was $99 \%$ similar to other $R$. solani AG-1 IA accessions (JX294339.1 (663/ 669 nucleotides) and AY270008.1 (621/623 nucleotides)) (Mora-Umaña et al. 2013; Fenille et al. 2003). This higher similarity to AG-1 IA accessions was confirmed through phylogenetic analysis (Fig. 2). Based on these results, the pathogen belongs to Rhizoctonia solani AG-1 IA.

All inoculated leaves presented typical leaf blight symptoms $72 \mathrm{~h}$ after inoculation, with a white mycelial web growth over the tissue. $R$. solani was eventually recovered, fulfilling Koch's postulates (Fig. 1d). The isolate was deposited in the Culture Collection of Microorganisms of Environmental and Agricultural Importance, Jaguariúna, Brazil (access code CMAA 1734).

This is the first report of Rhizoctonia solani causing leaf blight on cassava. The proximity of the affected crop to the native forested area infers that the pathogen may come from other hosts of the forest ecosystem. Recently, evidence has been 


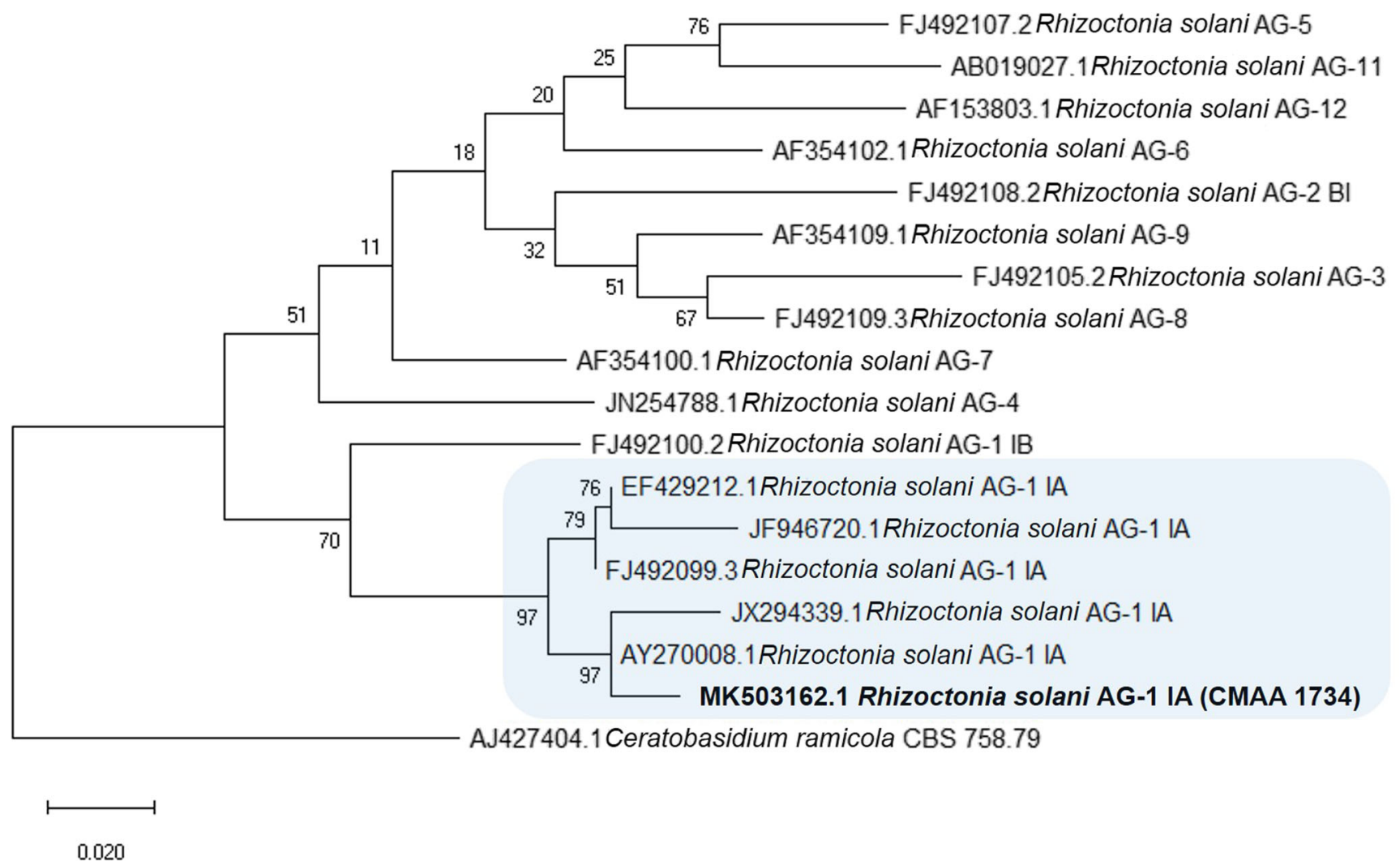

Fig. 2 Phylogenetic relationship among the isolate CMAA 1734 pathogenic for cassava (GenBank accession no. MK503162.1, in bold), and several Rhizoctonia solani AGs. Accession nos. FJ492107.2, AB019027.1, AF153803.1, AF354102.1, FJ492108.2, AF354109.1, FJ492105.2, FJ492109.3, FJ492100.2, and FJ492099.3 are from

reference strains. Ceratobasidium ramicola CBS 758.79 represents the outgroup. The phylogenetic tree was constructed with MEGA $X$ by using the Maximum likelihood method. Scale bar represents number of substitutions per site

demonstrated that $R$. solani AG-1 IA populations are capable of emerging as new strains with host specialisation, leading to host shift on neighbouring crops, with high probability of accelerated evolution (Mesa et al. 2015). The yield loss caused by this disease can have an extensive impact on the Amazon region, as the cultivation of cassava is one of the most important crops for local trade and subsistence, with substantial family farming traits.

Acknowledgements Bernardo de Almeida Halfeld-Vieira thanks the National Council for Technological and Scientific Development (CNPq) for his fellowship.

\section{References}

Ceresini PC, Fenille RC, Souza NL (1996) Associação de Rhizoctonia spp. binucleadas e de $R$. solani Kühn GA 4 HGI a vagens de amendoinzeiro (Arachis hypogaea) no estado de São Paulo. Summa Phytopathol 22:145-156

Fenille RC, Ciampi MB, Kuramae EE, Souza NL (2003) Identification of Rhizoctonia solani associated with soybean in Brazil by rDNA-ITS sequences. Fitopatol Bras 28:413-419. https://doi.org/10.1590/ S0100-41582003000400011

Kumar S, Stecher G, Li M, Knyaz C, Tamura K (2018) MEGA X: molecular evolutionary genetics analysis across computing platforms. Mol Biol Evol 35:1547-1549. https://doi.org/10.1093/molbev/msy096

Mesa EC, Ceresini PC, Molina LMR, Pereira DAS, Schurt DA, Vieira JR, Poloni NM, Mcdonald BA (2015) The Urochloa foliar blight and collar rot pathogen Rhizoctonia solani AG-1 IA emerged in South America via a host shift from rice. Phytopathology 105:1475-1486. https://doi.org/10.1094/ PHYTO-04-15-0093-R

Mora-Umaña F, Barboza N, Alvarado R, Vásquez M, Godoy-Lutz G, Steadman JR, Ramírez P (2013) Virulence and molecular characterization of Costa Rican isolates of Rhizoctonia solani from common bean. Trop Plant Pathol 38:461-471. https://doi.org/10.1590/S198256762013000600001

Moura EF, Farias Neto JT, Sampaio JE, Silva DT, Ramalho GF (2013) Identification of duplicates of cassava accessions sampled on the north region of Brazil using microsatellite markers. Acta Amazon 43:461-468. https://doi.org/10.1590/ S0044-59672013000400008

Parmeter JR, Sherwood RT, Platt WD (1969) Anastomosis grouping among isolates of Thanatephorus cucumeris. Phytopathology 59:1270-1278

Q-bank (2019) Fungi-ITS amplification and sequencing. http://www.qbank.eu/Fungi/LocalFiles/Latest/DNA Barcoding Fungi ITS.pdf/. Accessed 2 Apr 2019

Ratnasingham S, Hebert PDN (2007) BOLD: the barcode of life data system (http://www.barcodinglife.org). Mol Ecol Resour 7:355-364. https://doi.org/10.1111/j.1471-8286.2007.01678.x

White TJ, Bruns T, Lee S, Taylor J (1990) Amplification and direct sequencing of fungal ribosomal RNA genes for phylogenetics. In: Innis MA, Gelfand DH, Sninsky JJ (eds) PCR protocols: a guide to methods and amplifications. Academics Press, San Diego, pp 315-322 